\title{
Employee benefit status from e-employee service
}

\author{
Şemseddin Gündüz $\mathbf{z}^{1}$ \\ Ahmet Naci Çoklar ${ }^{2}$
}

\begin{abstract}
The internet is the one of the most important global network and information source in information age. The internet has changed employee's life enormously. The purpose of this study is to clarify the benefitting situations of employees from e-employee services. For this purpose, a 20 -item data collection tool, based on the e-employee services put forward by the Information Council Turkey was developed. Maintained measurement tool was applied on 515 employees residing different regions and provinces of Turkey in the 2014 academic year. As a result, it was observed that employees benefitted from social, health and education oriented services of eemployee at "medium frequency", whereas they "rarely" benefitted from the economic-oriented services of e-employee. It was found that women used e-employee services more than men. 30year of age and younger people used e-employee services more often than older people. In addition, those who have higher incomes use e-employee services more frequently than those who have medium or low incomes. Those working in education and finance sectors benefit from the eemployee services more often than those in other sectors.
\end{abstract}

Keywords: E-employee; internet use; e-employee services; income; finance sector.

\section{Introduction}

The rapid developments occurring in information and communication, is increasing the use of the internet as well. Every day, the internet use is spreading everywhere, from education to finance, military to health and from the market place to entertainment industry. According to TurkStat data, internet use rate among the 19-74-age group reached to $48.9 \%$ in 2013 while it was $30 \%$ in 2007 in Turkey, a country with a population approaching 80 million. (TurkStat, 2013). This increase in a six -year period is remarkable. Considering the widespread use of mobile devices, the Internet is expected to affect the lives of people much more.

The labour force participation rate In Turkey rated 50,1\% with a 0,1 point increase in the December period of 2013 compared to the same period of the previous year. The labour force participation rate was $70.9 \%$ in men and $29.9 \%$ in women. While the distribution of the people who were employed in 2004 was $29.1 \%$ in agriculture, $20.0 \%$ in industry, $4.9 \%$ in construction and $46.0 \%$ in service sector, this ratio fell nearly 6 points for agriculture whereas it increased 4 point for the service sector by the end of 2013. This rate for those who graduated from higher education institutions is $79.3 \%$, for vocational high school graduates is $62.9 \%$, for high school graduates $51.6 \%$, for less than high school graduates is $47.4 \%$ and it was $18.7 \%$ for Illiterate types. $65.5 \%$ of workers were regular or casual employee, $4.4 \%$ employer; $18.7 \%$ Self- employed and $11.4 \%$ were the unpaid family workers. (TurkStat, 2013b).

\footnotetext{
1 Assist.. Prof. Dr., Necmettin Erbakan University, Ahmet Keleşoğlu Education Faculty, Computer Education and Instructional Technologies Department, semsedding@gmail.com

2 Assoc. Prof. Dr., Necmettin Erbakan University, Ahmet Keleşoğlu Education Faculty, Computer Education and Instructional Technologies Department, ahmetcoklar@hotmail.com
} 
Gündüz, S.., \& Çoklar, A. N. (2017). Employee benefit status from e-employee service. Journal of Human Sciences, 14(2), 1799-1811. doi:10.14687/jhs.v14i2.4563

According to the Statistics Institute of Turkey, the rate of the internet use of the labour force in Turkey is $57.8 \% .67 .5 \%$ of the paid, salaried or casual employees, $78.6 \%$ of employers, $33.8 \%$ of the self-employed, $20.8 \%$ of unpaid family workers, and $55.6 \%$ of the unemployed use the internet (TurkStat, 2013b). The distribution of individuals using the Internet according to the types of their activities on the Internet is as follows (TurkStat, 2013):

\section{Table 1}

Type distribution of activities individuals carried out on the internet

\begin{tabular}{llll}
\hline Internet-related transactions & Total & Male & Female \\
\hline Search engine use to get information & 96.5 & 96.4 & 96.6 \\
E-mail sending with file attachments & 59.5 & 61.4 & 51.1 \\
Sending messages to chat rooms or virtual discussion forums & 40.3 & 43.5 & 35.5 \\
Using the Internet for phone calls & 19.3 & 20.2 & 17.9 \\
Music and film exchange through a sharing program & 20.0 & 21.9 & 17.1 \\
Designing a website & 5.00 & 6.40 & 3.00 \\
Uploading music, pictures, movies, text or games to a website & 34.1 & 36.4 & 30.6 \\
Changing the security settings of the internet browser & 20.5 & 23.4 & 16.1 \\
None & 2.40 & 2.30 & 2.60 \\
\hline
\end{tabular}

Internet-based services to be used by individuals were defined in the e-community study report carried out with students, employees and the retired, in the Middle East Technical University by the Turkish Information Council (TIC) in 2004 (TIC, 2004). According to the report, eemployee services mean carrying out processes done in the daily life via the Internet in an easier and more practical way and consist of a total of four sub-dimensions. In Table 2, the subdimensions making up the-employee services, operations in the sub-dimensions and comparison of their application way with traditional methods can be seen.

Table 2

Comparison of e-employee applications with traditional methods

\begin{tabular}{|c|c|c|}
\hline & Employee ( E-individual) & Employee (individuals) \\
\hline & What and How & What and How \\
\hline $\begin{array}{l}\text { Social } \\
\text { Family } \\
\text { Communication }\end{array}$ & via $\mathrm{E}$-mail, video conferencing & Overseas communication; mail, by phone \\
\hline Cultural Relations & Event tracking, e-ticket & By going there or media monitoring \\
\hline Friends Circle & $\begin{array}{l}\text { E-mail, video conferencing and inexpensive } \\
\text { communication }\end{array}$ & Phone calls or face to face communication \\
\hline Health & $\begin{array}{l}\text { Communication with the doctor } \\
\text { Disease surveillance and getting informed } \\
\text { Appointment / Receiving test results }\end{array}$ & $\begin{array}{l}\text { Phone calls or face to face } \\
\text { Limited research through books or } \\
\text { acquaintance doctor }\end{array}$ \\
\hline $\begin{array}{l}\text { Education } \\
\text { Individual } \\
\text { development } \\
\text { School - parent } \\
\text { communication }\end{array}$ & $\begin{array}{l}\text { Review of the meeting and the decisions } \\
\text { taken through Parents' Association' } \\
\text { Webpage } \\
\text { Monitoring the student's grades }\end{array}$ & $\begin{array}{l}\text { Going there or investigating } \\
\text { Going there } \\
\text { By phone or face to face }\end{array}$ \\
\hline Economy & $\begin{array}{l}\text { Banking transactions } \\
\text { Payments of bills and taxes } \\
\text { Citizenship services } \\
\text { Online working hours } \\
\text { Shopping }\end{array}$ & $\begin{array}{l}\text { Going there } \\
\text { Going there } \\
\text { Going there } \\
\text { Not applicable } \\
\text { Going there }\end{array}$ \\
\hline
\end{tabular}




\subsection{Importance of the Internet for Employees and New Competencies Brought}

The Internet has become to have a say more in every aspect of daily life especially with internet enabled mobile devices (Lenhart, Purcell, Smith \& Zickuhr, 2010). Needs and life skills of people have started to happen more in the internet environment in this age of so-called the internet age. In this context, the rapid development of the internet has also brought radical changes in people's lifestyles, and these changes have started to become a necessity (Earl \& Kimport, 2011). Assignments and source of information are now being directed to digital resources in educational environments, government operations are directed to e-government services, appointments and results information in health and result services have become to be made on the internet. The internet with a very important volume of transactions has now become a medium which is used by many employers in terms of trade (Ward, Sipior \& Volonino, 2016). When considered as a whole, the internet has now become an important medium of social life and using this medium started to become increasingly very imperative rather than a preference. The internet which is preferred more by young people with the impact of mobile devices and social networks, in particular requires major changes in employee qualifications as well (Lenhart et al., 2010). Popescu (2015) while stating that there is a global and industrial internet media today and it has come to a very important aspect in terms of the world economy, also proposed employees to have the proficiency to adapt to this world and show improvement. Also Quoquab, Salam and Halimah (2015) suggest that cyber loafing reduces the efficiency of workers, and it is important to use the internet consciously. Akman and Mishra (2015) stated that the internet needs to be used consciously by today's employees and required competences need to be gained for it. Mahatanankoon (2002) advises that the internet use awareness of the employee to be raised in order to increase their efficiency at workplace. Saran and Zavarsky (2009) express that raising the awareness of employees by institutions will increase the efficiency in the use of the Internet. In this respect, the determination of employees' e-sufficiency and raising their awareness will provide both personal convenience and also enhance the efficiency in the institutional sense. From this point, determining the issues to be good or bad in the context of the services offered on the internet is important in terms of increasing the training planning and the efficiency of institutions in this direction.

There are some researches on the internet use (Kabadayi, 2006) and competencies of employees (Moussa, 2015 Alampay \& Hechanova, 2010). Akman and Mishra (2015) developed a model intended for the gender and profession of employees that affect their use of the internet. They stated that both variables affect the use of the internet according to the data gained from 212 employees. Rice (2006) and Baym, Zhang Kunkel, Ledbetter and Lin (2007) stated that women use the internet more often than men in terms of the internet usage. Walter (2017) stated that different occupational groups might be affected differently by the use of ICT in the globalizing world. On the other hand, Wang Luo, Gao and Kong (2012) refers to the impact of lifestyle on the internet use. It is thought that with this aspect, lifestyle of individuals from different professions might differentiate and they may benefit from e-employee competencies differently. In this respect, the diversity of e-employee competencies according to sex and professional groups was investigated in this research. On the other hand, the internet use is shown in the literature to be important also according to age (Porter \& Donthu, 2006; Zhang, 2005; Hills \& Argyle, 2003). Prensky (2001) stated that use of technology among generations today differs, and the new generation has the competency to use technology more. Finally, the relationship between income and internet use was investigated. Especially, employees' having different income levels is thought to change their lifestyle and e-employee competency. Thus, File (2013) and White (2013) stated that income was important for adults for the use of the internet. Also, the internet usage rates can vary based on monthly income according to data obtained from TurkStat (2013b). Therefore, income was another variable studied for the e-employee competencies. 


\subsection{Importance of Research}

With the increased availability and speed of the Internet come new ways of disseminating interactive multimedia learning modules and possibilities for integrating information and communication technologies into the society (Kabadayi, 2012). Many of the concepts in the community are being transformed by adding the letter " $\mathrm{e}$ " at the beginning of the word. Eemployee is based on employees' doing daily life activities in the internet environment.

It is thought that individuals' being productive in the institutions they work is associated with their being able to use information and communication technologies. In this study, we investigated at what level employees benefit from the social, health, education and economic sub-dimensions of e-employee services. Research is important as it highlighting the impact of the Internet on everyday life, competencies of employees' internet usage and revealing e-employee activities on the internet. Benefitting levels of employees according to their sex, age, occupational field and income level were analyzed. It is also thought to be important in terms of showing direction of the development of eemployee activities to be presented.

\subsection{Research Objectives}

The purpose of this study is to reveal the benefit status of employees from e-employee services offered in the internet and the relationship between the benefit status of employees from eemployee services and their personal characteristics. For this purpose, we looked for answers to the following questions:

1. What is the benefit status of employees of e-employee services?

2. What is the benefit status of employees from e-employee services in terms of following sub-dimensions?
a. Social
b. Health
c. Education
d. Economy

3. Is there a significant difference of the benefit status from employees of e-employee services in terms of following variables?
a. Sex
b. Age
c. occupational fields
d. income level

\section{Methodology}

There is information about the model, population and sampling of the research, data collection tools and data analysis in this section.

\subsection{Research Model}

The scan model was used in this study, trying to determine the relationship between the benefit status of employees from the e-employee services and their personal characteristics. The scanning model is the quantitative research approach to demonstrate a situation that existed in the past and still exists as it is and consists of two dimensions for a single relationship (Creswell, 1994). The singular scanning model was used for qualifications of employees' e-employee, and the relational scan method was used for investigating these competencies according to gender, age, occupation and income level. 


\subsection{Population and Sampling}

The population of the study consists of individuals working in the province of Konya by the end of 2011 and using the Internet. Due to the size of the population, sampling and simple random sampling method was used. Simple random sampling method is the sample selection process completely at random, which is capable of representing a population with its size (Ozmen, 2000). For this purpose, of the schools located in the city center of Konya, three different primary schools in different districts were determined randomly in the 2014 academic year. In addition, because of large sampling, a survey developed for the parents of $6^{\text {th }}$ grade students of the elementary school was surveyed. We reached to a total of 587 employees, but 72 data were declared invalid for the reasons such as leaving blank, declaring not using the internet and marking the same options, so 515 employees were included in the study. Demographic information of the participants is shown in Table 3:

\section{Table 3}

Demographic information of participants

\begin{tabular}{llcc}
\hline & & Frequency & $\begin{array}{c}\text { Percent } \\
(\boldsymbol{\%})\end{array}$ \\
\hline Gender & Male & 402 & 78.1 \\
& Female & 113 & 21.9 \\
& Total & 515 & 100 \\
\hline Age & 30 and less & 72 & 14.0 \\
& Between 31 and 40 & 196 & 38.1 \\
& 41 and over & 247 & 48.0 \\
& Total & 515 & 100 \\
\hline Occupational field & Health & 52 & 10.1 \\
& Education & 96 & 18.6 \\
& Finance & 44 & 8.5 \\
& Service & 79 & 15.3 \\
& Civil Servant & 90 & 17.5 \\
& Workers and Tradesmen & 154 & 29.9 \\
& Total & 515 & 100 \\
\hline Income Level & Low & 116 & 22.5 \\
& Medium & 272 & 52.8 \\
& High & 127 & 24.7 \\
& Total & 515 & 100 \\
\hline
\end{tabular}

\subsection{Data Collection Tools}

A data collection tool used in the research consisted of two parts including a personal information form and an e-employee survey.

Personal Data Form: It is the section containing question items about gender, age, occupation and income level and used for obtaining the information to be associated with employee's benefit status of e-employee services.

E-employee Survey: A questionnaire consisting of 20 items was developed by researchers in order to define the benefit status of employee's from e-employee services. Employees were asked for each item how often they used the related e-employee service in the measurement tool. When preparing the survey, it was based on the e-employee final report prepared by the Turkish Information Council (TIC). In the mentioned study, e-employee was examined in four dimensions including social, health, education and economy. There are 6 items in the social dimension, 3 in health, 4 in education and 7 items in the economic dimension. Having been based on these items, 
the e-employee survey was prepared by researchers. It was examined by expert in order to ensure the content validity of the questionnaire. 3 items from the questionnaire was revised and rewritten after taking feedback from 3 experts from different universities working in the field of Computer Training. 25-people pilot implementation was conducted in order to determine the reliability of the questionnaire. At the end of the implementation the internal consistency coefficient Cronbach's alpha value was calculated as 79 , which is found to be acceptable by some research (Kabadayi, 2016).

\subsection{Data Analysis}

When transferring the items in the data collection tool in the computer, responses given in five-point Likert form were scored as "I never use, 1", "I rarely use, 2", "I use it at medium frequency, 3", "I often use it, 4" and "I use it very often, 5". 5 column 4 range logic was used in order to evaluate the arithmetic average range. A range value was $4 / 5=0.8$. Accordingly, the frequency of use was evaluated according to Table 4.

\section{Table 4}

E- employee services assessment criteria

\begin{tabular}{ll}
\hline Data range & Frequency of Use Assessment Criterion \\
\hline $1.00-1.80$ & Never \\
$1.81-2.60$ & Rarely \\
$2.61-3.40$ & Medium frequency \\
$3.41-4.20$ & Often \\
$4.21-5.00$ & Very often \\
\hline
\end{tabular}

Percentage, frequency, arithmetic average and standard deviation descriptive statistics were used to determine the benefit status of Employees from e-employee services. The independent samples $t$ test was used to determine the frequency of use of e-employee services whether they differed by gender or not. The One Way ANOVA test was used to determine the frequency of use e-employee services whether they differed by the occupational field, age and income levels or not. Furthermore, the Levene test was used to determine the homogeneity of the groups. Of PostHoc tests Scheffe was used in the groups that shows homogeneity in order to determine between which groups there is a difference, whereas the Dunnet 's C Scheffe test was used in the groups that doesn't show homogeneity. The significance level for all analyzes was .05. SPSS 21.0 (Statistical Package for the Social Sciences) software package was used in the statistical analysis of the research.

\section{Results}

Competencies of employees for e-employee and their states according to different variables of are given in headings.

\subsection{Benefit Status of Employees from e-Employee Services}

It was analyzed at what frequency the students used the e-student services, according to the purpose of the study in which 515 employees from six different sectors and the findings are given in Table 5: 
Gündüz, Ş., \& Çoklar, A. N. (2017). Employee benefit status from e-employee service. Journal of Human Sciences, 14(2), 1799-1811. doi:10.14687/jhs.v14i2.4563

\section{Table 5}

Benefit frequency of employees from e-employee services

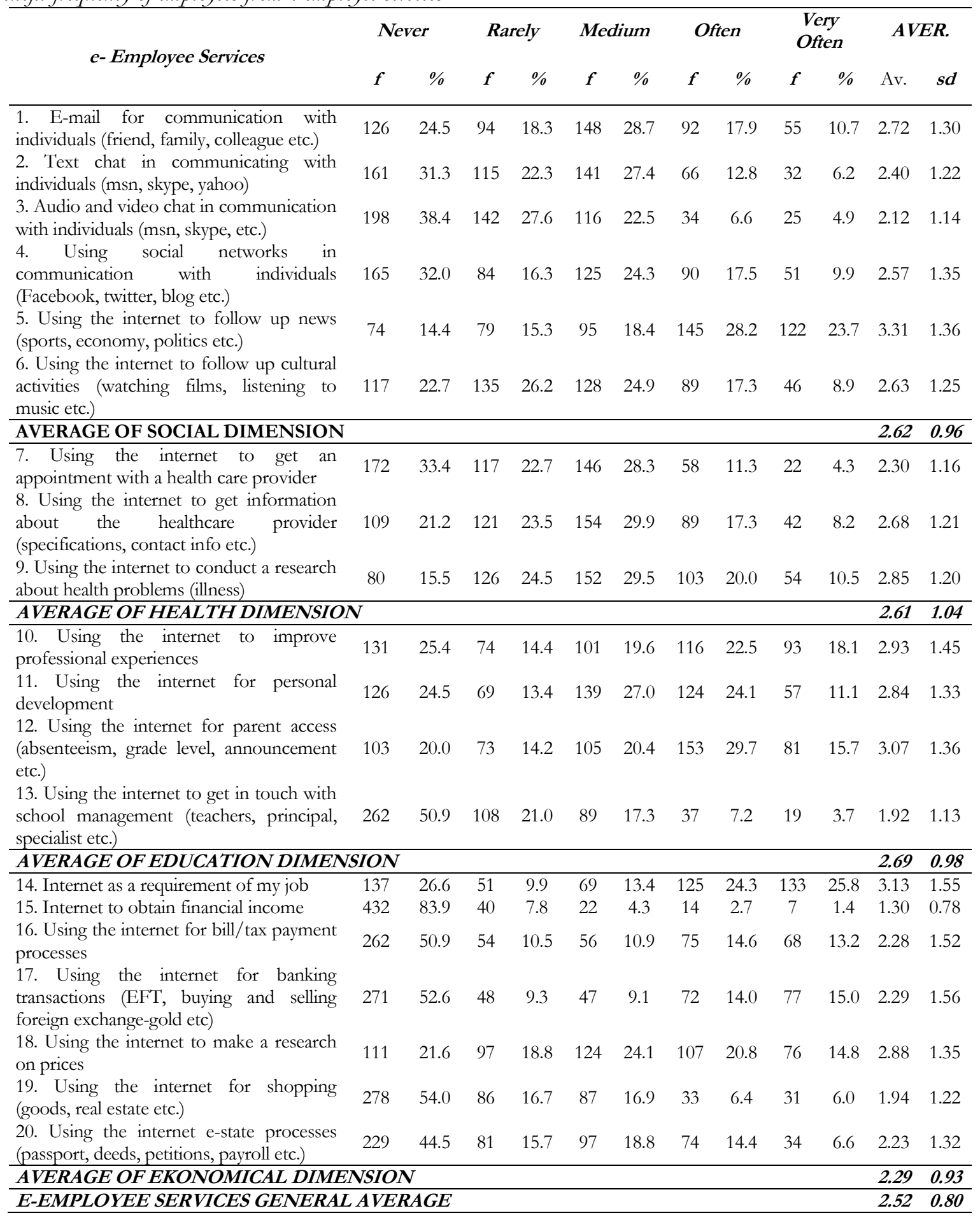

Employees "rarely" use e-employee services. When the table 5 is analyzed in terms of subdimensions, it can be seen that employees use e-employee services for educational, social and health purposes, "medium frequency". E-employee services for economical purposes are "rarely" used. None of the items making up the scale was marked as "often" or "very often" and it is important for the aspect to demonstrate that the state of employees using e-employee services is low.

When items in the social dimensions are examined, it can be seen that employees use the internet at "medium frequency" for following up the news; for cultural activities such as movie 
watching, music listening and for communication purposes with individuals such as friends, family and colleagues. Of these items, using the internet for following up news such as sports, economics, and politics as well as news scored highest among all item is also significant. On the other hand, it was stated that employees "rarely" used the internet for communication via text or audio-video chat and social networks.

When the items in the health dimension are analyzed, we can see that internet was used by employees at "medium frequency" for conducting a research about health problems and getting information about the health care provider. The item employees "rarely" use the internet for was making an appointment with your health care provider.

Educational purpose activities such as professional development, personal development and parent access processes were the most commonly used e-employee competences among the eemployee services. Employees use the internet at "medium frequency" to follow up parents processes, to improve their professional experiences, and provide personal development. It was also found that they "rarely" use the internet to communicate with individuals such as their children's teachers, the school principal.

The averages of e-employee services for economic purpose where the least frequently used items take place are also varied. Most of the employees used the internet at "medium frequency" for the purpose of a requirement of their job objectives and using the internet to make a research on prices. E-employee competences that took place under "rarely" medium are using the internet for banking transactions processes such as EFT, buying and selling foreign exchange and gold, for bill/tax payment processes for e-state processes such as passports, deeds, official documents and they "rarely" used the internet for goods, real estate, shopping etc. Among the e-employee competencies that employees "never" use is use the internet to generate income. Employees' not seeing the internet as a medium to generate revenue is an important finding.

\section{Gender \\ 3.2. Findings Related to Benefit Status of Employees from e-Employee Services by}

In this study, It was examined that whether the benefit status of employees from e-employee services change according to gender or not. For this purpose the $t$ test was performed to determine whether there are differences between the benefitting scores of men and women from e-employee services. The findings are shown in Table 6.

Table 6

Data regarding to benefit status of employees from e-employee services by gender

\begin{tabular}{lccccc}
\hline Group & $\mathbf{N}$ & Average & $\begin{array}{c}\text { Standard } \\
\text { Deviation }\end{array}$ & $\mathbf{t}$ & $\mathbf{p}$ \\
\hline Male & 402 & 2.47 & .81 & 2.41 & $.01^{*}$ \\
Female & 103 & 2.68 & .76 & & \\
\hline
\end{tabular}

As seen in Table 6, the average values of male and female employees' benefit status from eemployee services are different. As a result of the t-test applied to find out if the difference was statistically significant or not, it was found out that the difference was meaningful $(t=2.41, p<.05)$. While women benefit from e-employee services at "medium frequency", male employees benefit from e-employee services at "rarely". In other words, women use e-employee services more often than men. 
Gündüz, S., \& Çoklar, A. N. (2017). Employee benefit status from e-employee service. Journal of Human Sciences, 14(2), 1799-1811. doi:10.14687/jhs.v14i2.4563

\subsection{Findings Related to Benefitting from e-Employee Services According to Professional Fields}

In the study, it was investigated if the benefit status of employees from e-employee services change according to their occupational field or not. The data related to the benefit status of employees from e-employee services according to the occupational field is shown in Table 7.

Table 7

Benefit status of employees from e-employee services average scores and standard deviation values

\begin{tabular}{lccc}
\hline Occupational Field & n & Average & Std. Deviation \\
\hline A- Education & 96 & 2.97 & .70 \\
B- Finance & 44 & 2.73 & .76 \\
C- Health & 52 & 2.62 & .75 \\
D- Civil Servant & 90 & 2.60 & .68 \\
E- Service & 79 & 2.26 & .75 \\
F- Worker / Craftsmen & 154 & 2.22 & .82 \\
\hline Total & 515 & 2.52 & .80 \\
\hline
\end{tabular}

According to the data in Table 7, employees working in educational, finance and health occupational groups benefit from e-employee services at "medium frequency", while employees working in service, civil servants and workers / craftsmen occupational groups benefit from eemployee services at "rarely" frequency. One-way variance analysis was conducted to test whether the arithmetic average between groups was statistically significant or not. The results of this analysis are shown in Table 8.

Table 8

One- way variance analysis results of benefit scores of employees from e-employee services according to their occupational fields

\begin{tabular}{lcccccc}
\hline Source & df & $\begin{array}{c}\text { Sum of } \\
\text { Squares }\end{array}$ & $\begin{array}{c}\text { Mean } \\
\text { Square }\end{array}$ & $\mathbf{f}$ & $\mathbf{p}$ & Difference \\
\hline Between groups & 41.650 & 5 & 8.330 & & & A-F, A-E, A-D, \\
Within groups & 292.273 & 509 & .574 & 14.507 & $.01 *$ & B-F, B-E, C-F \\
Total & 333.923 & 514 & & & & \\
\hline
\end{tabular}

In Table 8, it can be observed that the difference between scores related to benefit of employees from e-employee services was significant $(\mathrm{F}=14.507, \mathrm{p}<.05)$. As a result of the Levene test, the variances were not found to be equal (Levene value $=1.318, \mathrm{p}<.05)$. Therefore Dunnet's $\mathrm{C}$ test was used to determine between which groups the difference stemmed from. Results of the analysis show that individuals working in the occupational groups of education and finance benefitted more than individuals working in the occupational groups of service as well as workers/craftsmen. In addition, individuals working in the occupational field of education benefitted from e-employee services more, comparing to individuals working in occupational groups of health and workers/craftsmen.

\subsection{Findings Related to Benefiting from e-Employee Services by Age}

The age is expressed as an important factor in the use of Internet and ICT technologies in some studies. Therefore, the benefit status of employees from e-employee competences was investigated according to according to the age of the employees. Data related to benefit status of employees from e-employee services according to their ages takes place in Table 9. 
Gündüz, Ş., \& Çoklar, A. N. (2017). Employee benefit status from e-employee service. Journal of Human Sciences, 14(2), 1799-1811. doi:10.14687/jhs.v14i2.4563

\section{Table 9}

Averages of benefit scores of employees from e-employee services according to their ages and their standard deviation values

\begin{tabular}{lccc}
\hline Age Range & $\mathbf{N}$ & Average & Std. Deviation \\
\hline A-30 and less & 72 & 3.00 & .74 \\
B-31- 40 & 196 & 2.46 & .80 \\
C-41 and over & 247 & 2.43 & .77 \\
\hline Total & 515 & 2.52 & .80 \\
\hline
\end{tabular}

Benefit status of individuals aged 30 or less from e-employee services can be seen to be more than individuals in other age ranges in Table 9. The one-way variance analysis was conducted to test whether the arithmetic averages between the groups were statistically significant or not (Table 10).

Table 10

One-way variance analysis results of employee benefit scores from e-employee services

\begin{tabular}{lcccccc}
\hline Source & df & $\begin{array}{c}\text { Sum of } \\
\text { Squares }\end{array}$ & $\begin{array}{c}\text { Mean } \\
\text { Square }\end{array}$ & F & P & Difference \\
\hline Between groups & 19.572 & 2 & 9.786 & & \multirow{2}{*}{$*$} & A-B, A-C \\
Within groups & 314.351 & 512 & .614 & 15.939 & $.01 *$ & \\
Total & 333.923 & 514 & & & & \\
\hline
\end{tabular}

As it can be seen in Table 10, benefit status of employees from e-employee services are differentiated according to their age $(\mathrm{F}=15.939, \mathrm{p}<.05)$. The Levene test for homogeneity of the groups was performed primarily to determine from which group or groups this difference emerged, and they were found to be homogeneous (Levene Value $=.543, \mathrm{p}>.05$ ). Therefore, Scheffe test of PostHoc tests was applied. According to analysis results, individuals who are at the age of 30 of younger took advantage of e-employee services relatively more than individuals between 31 and 40 ages and the ones at the age of 41 and over. However, there is no difference between the benefit status of employees from e-employee services of individuals of 31-40 ages and that of at the age of 41 and over.

\subsection{Findings Related to Employees' Benefit from E-Employee Services According to their Income Levels}

The impact of economically income level on the utilization of e-employee services was investigated. For this purpose, employees were asked to write down their monthly average income and, a classification was made according to the low, medium and high levels of income (Table 11).

\section{Table 11}

Descriptive statistics on the e-employee services and income levels

\begin{tabular}{lccc}
\hline Income Level & $\mathbf{n}$ & Average & Std. Deviation \\
\hline A- Low & 116 & 2.04 & .71 \\
B- Medium & 272 & 2.58 & .79 \\
C- High & 127 & 2.81 & .71 \\
\hline Total & 515 & 2.52 & .80 \\
\hline
\end{tabular}

Employees' benefit status from e-employee services differ according to their income level; it was observed that as the income level increased, benefit from e-employee services also increased (Table 11). The one-way variance analysis was conducted to test if the difference was significant or not and the results are given in Table 12 . 
Gündüz, Ş., \& Çoklar, A. N. (2017). Employee benefit status from e-employee service. Journal of Human Sciences, 14(2), 1799-1811. doi:10.14687/jhs.v14i2.4563

Table 12

Employee benefit scores from e-employee services according to their income levels

\begin{tabular}{lcccccc}
\hline Source & $\mathbf{d f}$ & $\begin{array}{c}\text { Sum of } \\
\text { Square }\end{array}$ & $\begin{array}{c}\text { Mean } \\
\text { Square }\end{array}$ & $\mathbf{F}$ & $\mathbf{p}$ & Difference \\
\hline Between groups & 37.898 & 2 & 18.949 & & & A-B, A-C, \\
Within groups & 296.024 & 512 & .578 & 32.774 & $.01 *$ & B-C \\
Total & 333.923 & 514 & & & & \\
\hline
\end{tabular}

The income level of employees has an impact on employees' benefit status from e-employee services $(\mathrm{F}=32.774, \mathrm{p}<.05)$. Applied Levene test have shown that groups were homogenous (Levene value $=2.145, \mathrm{p}>.05$ ), different groups were investigated by the Scheffe test of PostHoc tests. Analysis results indicated that there were differences between all groups. In terms of income levels, high-income individuals take advantage from e-employee services more than medium income level individuals and low income level individuals; and medium level individuals benefit more than low income individuals. Therefore, as the income level of employees increased, utilization situations of employees from e-employee services also increased.

\section{Results and discussion}

The Internet has become a part of life nowadays. It makes people's transactions easier with the services it offers for people. Many procedures such as banking transactions, following up up-todate information, additional business opportunities, using the internet for development, student tracking and communication can also be done easily from the internet as can be done with traditional methods. E-Employee services, in this context, mean benefitting from the internet with the aim to raise the quality of life of employees. Employees benefit from e-employee services with educational purposes at "medium frequency", whereas they "rarely" benefit from e-employee services with social, health and economy purposes. It has been observed in this study, in which frequency of e-employee services use was investigated with their sub dimensions, that employees from different sectors of life generally "rarely" benefitted from these services. We can say that employees aren't able to benefit enough from e-employee competences.

At the end of the research, it was concluded that female employees benefited from eemployee services more often than male employees. These findings are similar to the literature. Research has shown that men and women use the internet for different purposes. Rice (2006) stated that women use the internet to get information about health more than men. Baym, Zhang, Kunkel, Ledbetter and Lin (2007) announced that women use the internet for the communication purpose more often than men.

On the other hand, benefit status of employees from e-employee services also show difference according to their profession. In particular, education, finance and health care professionals take advantage of e-employee services at "medium frequency". In contrast, workers / craftsmen, service workers and civil servants "rarely" benefit from these services. In this respect, the possibilities professional sector offers such as ICT literacy, official working hours lead employees to e-employee services. On the other hand, no matter what profession area from, that employees don't benefit enough from the e- competences of e-employee is also noteworthy.

Age and knowledge are important factors in the use of communication technologies, in other words ICT literacy. In this respect, the impact of age benefitting from e-employee services was also investigated and concluded that individuals aged 30 or less make use of e-employee services more. All sector workers aged 31 and over do not benefit enough from these services. Therefore, it can be suggested that all sector workers aged especially 31 and over be informed to raise awareness of workers about the e-employee services. These findings are similar to the literature. Studies reported that young people used the Internet more frequently than the elderly. (Hills \& Argyle, 2003; Porter 
\& Donthu, 2006) . Zhang (2005) announced that elderly people found the internet less useful comparing to young people.

Finally, the variation of benefit status of e-employee services was also investigated according to the income levels of employees. It is concluded that the more the income level of employees increase, the more they benefit from e-employee services and the more it decreases, the less they take advantage of it. The income level is the most determinant of benefitting from e-employee services. It can be interpreted that the income level affects e-employee services. Emphasizing this situation, employees can be lead to benefit from e-employee services. Porter and Donthu, (2006 ) also reported in a similar study they carried out that employees with high income levels use the internet more often than the ones with low income levels.

\section{References}

Akman, I., \& Mishra, A. (2015). Predictive effect of gender and sector differences on internet usage among employees. Engineering Economics, 21(3), 295-305.

Alampay, E. A., \& Hechanova, R. M. (2010). Monitoring employee use of the internet in Philippine organizations. The Electronic Journal on Information Systems in Developing Countries, 40(5), 1-20.

Baym, N. K., Zhang, Y. B., Kunkel, A., Ledbetter, A., \& Lin, M. C. (2007). Relational quality and media use in interpersonal relationships. New Media \& Society, 9 (5), 735-752.

Creswell, J. W. (1994). Research design: Qualitative and quantitative approaches. Thousand Oaks: Sage.

Duggan, M., Ellison, N. B., Lampe, C., Lenhart, A., \& Madden, M. (2015). Social media update 2014. Pew Research Center., 19. Accessed on January, 08, 2016. Retrieved from $<$ http://www.pewinternet.org/files/2015/01/PI_SocialMediaUpdate20144.pdf>.

Earl, J., \& Kimport, K. (2011). Digitally enabled social change: Activism in the internet age. Cambridge, MA and London: The Mit Press.

File, T. (2013). Computer and internet use in the United States. Current Population Survey Reports, P20568. US Census Bureau, Washington, DC.

Hills, P., \& Argyle, M. (2003). Uses of the internet and their relationships with individual differences in personality. Computers in Human Behavior, 19. 59-70.

Kabaday1, A. (2006) Analyzing Pre-School Student Teachers' and Their Cooperating Teachers' Attitudes towards the Use of Educational Technology, TOJET: The Turkish Online Journal of Educational, 5(4), Article 1.

Kabaday1, A. (2012) Investigating preservice pre-school teachers' attitudes to internet use, Croatian Journal of Education, 14 (2), 233,255.

Kabadayi, A. (2016). A Suggested In-service Training Model Based on Turkish Preschool Teachers' Conceptions for Sustainable Development, Journal of Teacher Education for Sustainability, 18(1), pp. 5-15.

Ko, C. H., Yen, J. Y., Chen, C. C., Chen, S. H., \& Yen, C. F. (2005). Gender differences and related factors affecting online gaming addiction among Taiwanese adolescents. Journal of Nervous and Mental Disease, 193(4), 273-277.

Lenhart, A., Purcell, K., Smith, A., \& Zickuhr, K. (2010). Social media \& mobile internet use among Teens and Young Adults. Millennials. Pew Internet \& American Life Project.

Mahatanankoon, P. (2002). Explaining production deviant use of the internet technology in the workplace: An integrated model. Dissertation Abstract International, 63, 03A.

Moussa, M. (2015). Monitoring employee behavior through the use of technology and issues of employee privacy in America. SAGE Open, 5(2), 2158244015580168.

Ozmen, A. (2000). Sampling methods in applied research Eskisehir: Anadolu University Press.

Popescu, G. H. (2015). The economic value of the industrial internet of things. Psychosociological Issues in Human Resource Management, 3(2), 86-92. 
Porter, C. E., \& Donthu, N. (2006). Using the technology acceptance model to explain how attitudes determine internet usage: The role of perceived access barriers and demographics. Journal of Business Research, 59(9), 999-1007.

Prensky, M. (2001, September/October). Digital natives, digital immigrants. On the Horizon, 9(5), 16.

Quoquab, F., Salam, Z. A., \& Halimah, S. (2015, August). Does cyberloafing boost employee productivity?. In Technology Management and Emerging Technologies (ISTMET), 2015 International Symposium, 119-122.

Saran, M., \& Zavarsky, P. (2009) A study of the methods for improving internet usage policies, cse. International Conference on Computational Science and Engineering, 3, 371-378.

TIC - Turkey Information Council. (2004). "e-Toplum Çalsşma Grubu Sonuç Raporu (e-Society Study Group Final Report)". II. Turkey Information Council. 30-31 May 2004, Ankara, Turkey: Middle East Technical University.

TurkStat. (2013a). "Information And Communication Technology (ICT) Usage Survey On Households And Individuals", Retrieved: 02 03, 2014. from http://www.tuik.gov.tr/PreTablo.do?alt_id=1028.

TurkStat. (2013b). "Labour Force Participation Rate Survey On Households And Individuals", Retrieved: 02 03, 2014. from http://www.tuik.gov.tr/ZipGetir.do?id=16005.

Walter, S. (2017). Globalization and the demand-side of politics: How globalization shapes labor market risk perceptions and policy preferences. Political Science Research and Methods,5(1), 5580 .

Wang, L., Luo, J., Gao, W., \& Kong, J. (2012). The effect of internet use on adolescents' lifestyles: A national survey. Computers in Human Behavior, 28(6), 2007-2013.

Ward, B. T., Sipior, J. C., \& Volonino, L. (2016). Internet jurisdiction for e-commerce. Journal of Internet Commerce, 15(1), 1-17.

White, P., \& Selwyn, N. (2013). Moving on-line? An analysis of patterns of adult internet use in the UK, 2002-2010. Information, Communication \& Society, 16(1), 1-27.

Wu, J. H., \& Wang, S. C. (2005). What drives mobile commerce?: An empirical evaluation of the revised technology acceptance model. Information \& Management, 42(5), 719-729.

Zhang, Y. (2005). Age, gender, and internet attitudes among employees in the business world. Computers in Human Behavior. 21(1), 1-10. 